\title{
The Propensity to Cycle Tool: An open source online system for sustainable transport planning
}

\section{Robin Lovelace University of Leeds}

\author{
Nikolai Berkoff \\ Independent web \\ developer
}

\author{
Anna Goodman \\ London School of \\ Hygiene and Tropical \\ Medicine \\ Ali Abbas \\ University of \\ Cambridge
}

\author{
Rachel Aldred \\ University of Westminster \\ James Woodcock \\ University of Cambridge
}

\begin{abstract}
Getting people cycling is an increasingly common objective in transport planning institutions worldwide. A growing evidence base indicates that high quality infrastructure can boost local cycling rates. Yet for infrastructure and other cycling measures to be effective, it is important to intervene in the right places, such as along 'desire lines' of high latent demand. This creates the need for tools and methods to help answer the question 'where to build?. Following a brief review of the policy and research context related to this question, this paper describes the design, features and potential applications of such a tool. The Propensity to Cycle Tool (PCT) is an online, interactive planning support system that was initially developed to explore and map cycling potential across England (see www.pct.bike). Based on origin-destination data it models cycling levels at area, desire line, route and route network levels, for current levels of cycling, and for scenario-based 'cycling futures.' Four scenarios are presented, including 'Go Dutch' and 'Ebikes,' which explore what would happen if English people had the same propensity to cycle as Dutch people and the potential impact of electric cycles on cycling uptake. The cost effectiveness of investment depends not only on the number of additional trips cycled, but on wider impacts such as health and carbon benefits. The PCT reports these at area, desire line, and route level for each scenario. The PCT is open source, facilitating the creation of scenarios and deployment in new contexts. We conclude that the PCT illustrates the potential of online tools to inform transport decisions and raises the wider issue of how models should be used in transport planning.
\end{abstract}

\section{Article History:}

Received: December 12, 2015

Received in revised

form: May 27, 2016

Accepted: August 18, 2016

Available online: December 6, 2016

Copyright 2016 Robin Lovelace, Anna Goodman, Rachel Aldred, Nikolai Berkoff, Ali Abbas, and James Woodcock. doi: $10.5198 /$ jtlu.2016.862

ISSN: 1938-7849 | Licensed under the Creative Commons Attribution - NonCommercial License 3.0.

The Journal of Transport and Land Use is the official journal of the World Society for Transport and Land Use (WSTLUR) and is published and sponsored by the University of Minnesota Center for Transportation Studies. 


\section{Introduction}

Cycling can play an important role in creating sustainable and equitable transport systems. Cycling already provides reliable, healthy, affordable, and convenient mobility to millions of people each day (Komanoff 2004) and is one of the fastest growing modes of transport in cities such as London, New York and Barcelona (Fishman 2016). There is mounting evidence about the external costs of cardominated transport systems (Han and Hayashi 2008; Shergold et al.2012), and the benefits of cycling (De Nazelle et al. 2011; Oja et al. 2011; Tainio et al. 2016). In this context there is growing interest, and in some cases substantial investment, in cycling infrastructure, including in countries with historically low rates of cycling.

Providing high-quality infrastructure can play a key role in promoting cycling uptake (Parkin 2012). Off-road cycle paths, for example, have been found to be associated with an uptake of cycling for commuting (Heinen et al. 2015). Overall there is growing evidence linking cycling infrastructure to higher rates of cycling (Buehler and Dill 2016). But where should this infrastructure be built? The central purpose of this paper is to highlight the potential of online, interactive and publicly accessible tools to improve the provision of locally specific evidence about where cycling has the greatest potential to grow. It does so with reference to the Propensity to Cycle Tool (PCT), an online planning support system funded by the UK's Department for Transport to map cycling potential (Department for Transport, 2015). The PCT is open source. This differs from other tools for assessing cycling potential (see the next section) and has wider implications for how models can and should be used in the transport decision making process (see the Discussion).

\section{The Propensity to Cycle Tool in context}

The PCT was developed alongside two branches of academic research: a) methodological developments for estimating cycling potential and b) Planning Support Systems (PSS). The subsequent overview of this policy and academic landscape places the PCT in its wider context and explains its key features.

\subsection{The policy context}

A number of factors influence the attractiveness of cycling for everyday trips (Parkin 2015; Pucher et al. 2010). However, the intervention that has received the most attention has been the construction of new cycle paths. In the UK context, devolved transport budgets mean that local authorities have some control over the design and implementation of cycling networks. While much of the road network budget allocated centrally, through Highways England, cycle paths tend to be commissioned and designed locally due to funding streams such as the Local Sustainable Transport Fund, described in the context of modal shift to cycling by Chatterjee et al. (2013). This, and the shorter distances and more flexible routes (e.g., through parks and along disused railways) that cycle paths can take increases the importance of high resolution map-based tools for cycling compared with motorised modes. Local transport budgets also increase demand for local cycling targets that open source tools such as the PCT could enable, as described in the Discussion.

Planning new cycle paths requires many decisions to be made, including in relation to the width (Pikora et al. 2002; Wegman 1979), quality (Heath et al. 2006), directness (CROW 2007) and geographic location of the paths. Yet while much guidance has been produced regarding physical design (Transport for London 2015; Welsh Government 2014), little work has explicitly tackled the question of where high quality infrastructure should be built (Aultman-Hall et al. 1997; Larsen et al. 2013; Minikel 2012). Within this policy context, the PCT focuses explicitly on the question of where to build rather than what to build, although it does provide evidence on potential capacity requirements across the route network. 


\subsection{Research into cycling potential}

There is an emerging literature exploring cycling rates and potential rates of growth. Much of this work is practitioner-led, as detailed in an excellent overview of developments in the USA (Kuzmyak et al. 2014). With the notable exceptions of (Larsen et al. 2013) and (Zhang et al. 2014), the methods reviewed in this section are not simultaneously route-based, systematic, quantitative and scalable, some of the key features of the PCT. The work can be classified in a number of ways, including by the main mechanism of the tool (e.g., facility demand or mode choice models), the format of its outputs (e.g., spreadsheet results, GIS-based map or on-line, interactive map) or by the main level of the input data used. In these terms, the PCT is based on a mode choice model (representing the shift to cycling from other modes) operating primarily at the origin-destination level, which provides outputs in an online, interactive map. For research into cycling potential (and the resulting models) to be useful for local transport planners, their spatial scale must coincide with that over which the planning process has some control. For this reason we focus on scale as the primary way of categorising research into cycling potential, highlighting the following prominent levels (the PCT best fits into the third).

- Area-based measures are based primarily on data at the level of administrative zones, which will vary depending on context. Outputs from these measures can assist with the location of sitespecific transport infrastructure such as cycle parking.

- Individual-based measures are based on survey data, typically a household travel survey. These are not always geographically specific and tend to be used to identify and categorise demographic groups in relation to cycling, such as near-market or as warranting tailored interventions, such as targeted cycle training schemes.

- Route-based measures use origin-destination data which can be used to create 'desire lines' and (using route allocation) estimates of existing and potential demand at each point on the road network.

This work is reviewed in relation to the PCT below and summarised in Table 1.

Parkin et al. (2008) presented an area-based measure of cycling potential using regression model to estimate the proportion of commuter trips cycled across wards in England and Wales. Factors associated with lower levels of cycling included road defects, high rainfall, hills and a higher proportion of ethnic minority and low-income inhabitants. Parkin et al. concluded that policy makers must engage with a mixture of physical and social barriers to promote cycling effectively, with the implication that some areas have lower barriers to cycling - and hence higher propensity to cycle - than others.

Zhang et al. (2014) created an individual-based model of cycling potential to prioritise where to build cycle paths to "achieve maximum impacts early on." The outputs of this model were aggregated to the level of 67 statistical zones in the study area of Belo Horizonte, Brazil, and used to generate a 'usage intensity index' for potential cycle paths. This, combined with survey data on cyclists' stated preferences on whether people would cycle were infrastructure provided along particular routes and origin-destination data on travel to work, was used to rank key routes in the city in terms of their cycling potential.

Larsen et al. (2013) created an area-based 'prioritization index' for Montreal, Canada. This was based on four variables: the area's current level of cycling, its cycling potential (estimated based on the shortest path between the origin and destination of short car trips from a travel survey), the number of injuries to cyclists, and locations prioritised by current cyclists for improvement (Larsen et al. 2013). These four were aggregated to the level of evenly spread cells covering the study area. The resulting heat map was used to recommend the construction or upgrade of cycle paths on specific roads.

Although the methods presented in preceding three paragraphs were developed in an academic context, most of the usable tools for estimating cycling potential are practitioner-led. Many of these may never have been documented in the academic literature, so the subsequent overview should not be regarded as comprehensive (see Kuzmyak et al.2014, and subsequent documents that cite this report). 
The Analysis of Cycling Potential (ACP) tool was developed by (Transport for London 2010) to produce heat maps of cycling potential across London, for all trip purposes. It is based a mode choice model of likelihood of trips being cycled and uses the characteristics of observed trips (e.g., time of day, characteristics of the traveller, distance) as the main input dataset. The results of the ACP have informed local cycling schemes, such as where to build new cycle hire stations but does not use origindestination data so is less relevant for route-based interventions.

A more localised approach is the Permeability Assessment Tool (PAT), which was developed by a transport consultancy (Payne 2014). The PAT is based on the concept of 'filtered permeability', which means providing a more direct route to people cycling than driving (Melia 2015). The PAT works by combining geographical data, including the location of popular destinations and existing transport infrastructure, with on-site audit data of areas that have been short-listed. Unlike the prioritisation index of Larsen et al. (2013), which is primarily aimed at informing a city-wide strategic cycling network, the results of the PAT are designed to guide smaller, site specific interventions such as 'contraflow' paths and cyclist priority traffic signals.

The Santa Monica model is an example of a direct facility demand model, which are based on "observed counts and context-driven regression models" (Kuzmyak et al. 2014). The model uses environmental explanatory variables such as employment density and speed limits of surrounding roads to estimate the dependent variable: walking and cycling activity (e.g., as recorded by screenline count devices). By adjusting regression parameters (e.g., based on areas that have experienced growth in cycling), such models can be used to "forecast demand levels for walk or bike at a point or intersection level" and "evaluate and prioritize projects" (ibid., p. 75).

Table 1: Summary of tools and methods to explore the geographical distribution of cycling potential. Levels of analysis refer to whether data is analysed at point $(\mathrm{P})$, area (A), origin-destination $(\mathrm{OD})$, route $(\mathrm{R})$, route network $(\mathrm{RN})$ or individual (I) levels.

\begin{tabular}{|c|c|c|c|c|c|c|}
\hline Tool & Scale & Coverage & $\begin{array}{r}\text { Public } \\
\text { access }\end{array}$ & $\begin{array}{r}\text { Format of } \\
\text { output }\end{array}$ & $\begin{array}{r}\text { Levels of } \\
\text { analysis }\end{array}$ & $\begin{array}{r}\text { Software } \\
\text { licence }\end{array}$ \\
\hline $\begin{array}{l}\text { Propensity } \\
\text { to Cycle } \\
\text { Tool } \\
\end{array}$ & National & England & Yes & Online map & $\mathrm{A}, \mathrm{OD}, \mathrm{R}, \mathrm{RN}$ & Open source \\
\hline $\begin{array}{l}\text { Prioritization } \\
\text { Index }\end{array}$ & City & Montreal & No & GIS-based & $\mathrm{P}, \mathrm{A}, \mathrm{R}$ & Proprietary \\
\hline $\begin{array}{l}\text { Permeability } \\
\text { Assessment } \\
\text { Tool }\end{array}$ & Local & $\begin{array}{l}\text { Parts of } \\
\text { Dublin }\end{array}$ & No & GIS-based & $\mathrm{A}, \mathrm{OD}, \mathrm{R}$ & Proprietary \\
\hline $\begin{array}{l}\text { Usage } \\
\text { intensity } \\
\text { index }\end{array}$ & City & $\begin{array}{r}\text { Belo Hor- } \\
\text { izonte }\end{array}$ & No & GIS-based & $\mathrm{A}, \mathrm{OD}, \mathrm{R}, \mathrm{I}$ & Proprietary \\
\hline $\begin{array}{l}\text { Bicycle } \\
\text { share model }\end{array}$ & National & $\begin{array}{r}\text { England, } \\
\text { Wales }\end{array}$ & No & Static & $A, R$ & Unknown \\
\hline $\begin{array}{l}\text { Cycling } \\
\text { Potential } \\
\text { Tool }\end{array}$ & City & London & No & Static & A, I & Unknown \\
\hline $\begin{array}{l}\text { Santa } \\
\text { Monica } \\
\text { model }\end{array}$ & City & $\begin{array}{r}\text { Santa } \\
\text { Monica }\end{array}$ & No & Static & $\mathrm{P}, \mathrm{OD}, \mathrm{A}$ & Unknown \\
\hline
\end{tabular}




\subsection{Planning support systems}

The methods and tools for estimating cycling potential outlined in Table 1 were generally created with only a single study region in mind. The benefit of this is that they can respond context-specific to practitioner and policy needs. However, the PCT aims to provide a generalisable and scalable tool, in the tradition of Planning Support Systems (PSS).

PSS were developed to encourage evidence-based policy in land-use planning (Klosterman 1999). The application of PSS to transport planning has been more recent, with a goal of "systematically [introducing] relevant (spatial) information to a specific process of related planning actions" (te Brömmelstroet and Bertolini 2008). The PCT is systematic in its use of national data for all parts of the study region (in this case England) and relates to a specific planning process - the creation of new and enhancement of existing cycle infrastructure.

PSS typically work by presenting evidence about the characteristics and needs of the study region in an interactive map. A central objective is to visualise alternative scenarios of change, and explore their potential impacts. The results of traditional scenario-based models are usually not locally specific (Lovelace et al. 2011; McCollum and Yang 2009; Woodcock et al. 2009). Online PSS can overcome this issue by using interactive maps (Pettit et al. 2013). The emergence of libraries for web mapping (Haklay et al. 2008) has facilitated online PSS, offering the potential for public access to the planning process. Transparency is further enhanced by making PSS open source, in-line with a growing trend in transport modelling (Borning et al. 2008; Novosel et al. 2015; Tamminga et al. 2012). In these ways, PSS can make evidence for transport planning more widely available, and tackle the issue that transport models are often seen as 'black boxes', closed to public scrutiny (Golub et al., 2013).

With reference to a publicly accessible online map-based PSS for strategic land use (and to a lesser extent transport) planning, Kahila-Tani et al. (2016) provide guidance on the wider public participation process: it should be transparent, influence real world decisions, be representative of citizens and allow independent participation. Although these criteria depend primarily on how the tool is deployed in practice (for example with regards to training resources and workshops facilitated by planning authorities to ensure that the tool the tool is used effectively), which are outside the scope of the current paper, the PCT certainly encourages transparency through its use of open data and open source software and allows independent participation through its publicly accessible online interface.

\subsection{National context and features of the Propensity to Cycle Tool}

In addition to the international policy and academic context, the PCT was influenced by the national context. It was commissioned by the UK's Department for Transport to identify "parts of [England] with the greatest propensity to cycle" (Department for Transport 2015). Thus the aim was not to produce a full transport demand or land use model, but to provide an evidence base to prioritise where to create and improve cycling infrastructure based on scenarios of change.

Local and national cycling targets are often based on a target mode share by a given date. ${ }^{1}$ However, there is little evidence about what this might mean for cycling volumes along specific routes. The PCT tackles this issue by estimating rate of cycling locally under different scenarios and presenting the results on an interactive map. Its key features include:

- Estimation of cycling potential at area, 'desire line' and route network levels.

- Route-allocation of OD (origin-destination) pairs by a routing algorithm specifically developed for cycling. This was done by CycleStreets.net, a routing service developed by cyclists, for cyclists.

\footnotetext{
${ }^{1}$ The local target in Bristol, for example, is for $20 \%$ of commuter trips to be cycled by 2020 . Manchester (10\% by 2025), Derbyshire (to double the number of people cycling by 2025) and London (to 'double cycling' by 2025) provide further examples of ambitious local time-bound cycling targets.
} 
- Visualisation of outputs at multiple geographic levels. The interactive map enables users to examine cycling potential at a very local level (e.g., just a few streets) or at a more regional level (e.g., across a large metropolitan area).

- Public accessibility of results and code. The tool is freely available online and developers are encouraged to modify the PCT (e.g., to create alternative scenarios) by provision of the source code underlying the PCT under the open source AGP License.

- The presentation of estimated health economic and carbon impacts under future scenarios, providing an evidence base that could be used in business cases for investment.

As with any tool, the PCT's utility depends on people knowing how to use it. For that reason training materials and a user manual are being developed to show how the tool can be used (see the 'Manual' tab in Figure 3 and pct.bike/manual.html).

\section{Data and methods}

This section describes the data and methods that generate the scenario data for the PCT, as summarised in Figure 1. The details of the model, which models the proportion of trips made by cycling per OD pair as a function of hilliness and distance, are described in the Appendix. The scenario-generation method is not included in the main text of the paper because it is the most context-specific aspect of the PCT: as outlined in the Discussion, we envision future uses of the PCT using different model parameters and even different functional forms relating distance, hilliness and other variables to the level of cycling, to generate scenarios of use for new contexts beyond the English case study described here. Central to the PCT approach is origin-destination (OD) data recording the travel flow between administrative zones. ${ }^{2}$ Combined with geographical data on the coordinates of the population-weighted centroid of each zones, these can be represented as straight 'desire lines' or as routes allocated to the transport network.

\subsection{Processing OD data}

The central input dataset was a table of origin-destination (OD) pairs from the 2011 Census. This was loaded from open access file wu03ew_v2. csv, provided by the UK Data Service. This captures the number of commuters travelling between Middle Super Output Area zones (MSOAs, average commuter population: 3300), by mode of travel (see Table 2). This dataset was derived from responses to the following questions in the 2011 Census for England and Wales: "In your main job, what is the address of your workplace?" (question 40) and "How do you usually travel to work? (Tick one box only, for the longest part, by distance, of your usual journey to work)" (Question 41). This dataset was enhanced by merging in information on the gender composition of cyclists in each OD pair (Dataset 1 in Figure 1); data at the area level on the background mortality rate (Dataset 2); and data at the OD pair-level on route distance $(\mathrm{km})$ and hilliness (average gradient, as a percentage) (Dataset 3). OD data was assigned to the transport network using the R package stplanr (Lovelace et al., 2016). See the Appendix for further details.

\subsection{Modelling baseline propensity to cycle}

The starting point for generating our scenario-based 'cycling futures' was to model baseline data on cycle commuting in England and Wales. We did this using OD data from the 2011 Census, and modelling cycling commuting as a function of route distance and route hilliness. We did so using logistic regression applied at the individual level, including squared and square-root terms to capture 'distance decay' - the non-linear impact of distance on the likelihood of cycling (Iacono et al. 2008) - and

\footnotetext{
${ }^{2}$ The size and uniformity of these depend on the country in question. In the UK the primary areal units for statistical data are output areas (OA), lower layer super output areas (LSOA) and middle layer super output areas (MSOA) (see webarchive.nationalarchives.gov.uk). The version of the PCT presented in this paper operates at the MSOA level.
} 
Dataset 1: Origin-destination (OD) pairs at the MSOA-level for all commute trips in England and Wales, stratified by method of travel to work and by gender, from the 2011 Census
Dataset 2: Background mortality rate for cyclists, merge in at the local authority level

Dataset 3: Fastest route distance $(\mathrm{km}) /$ hilliness (\% incline) of each OD pair <30km Euclidean distance, from CycleStreets.net.

Data processing (details in Appendix)

1. Collapse flows $>30 \mathrm{~km}$ fastest-route distance, or ending outside England or Wales, into an 'other' category.

2. Estimate distance and hilliness for OD pairs that start and end in the same zone Assign cycling distance to 'no fixed workplace' / 'other' flows

3. Apply propensity to cycle equations : generate changes in cycling in each OD pair in 4 scenarios. Calculate changes in walking/driving in 4 scenarios.

4. Calculate HEAT for health benefits.

5. Calculate $\mathrm{CO}_{2}$ reductions.

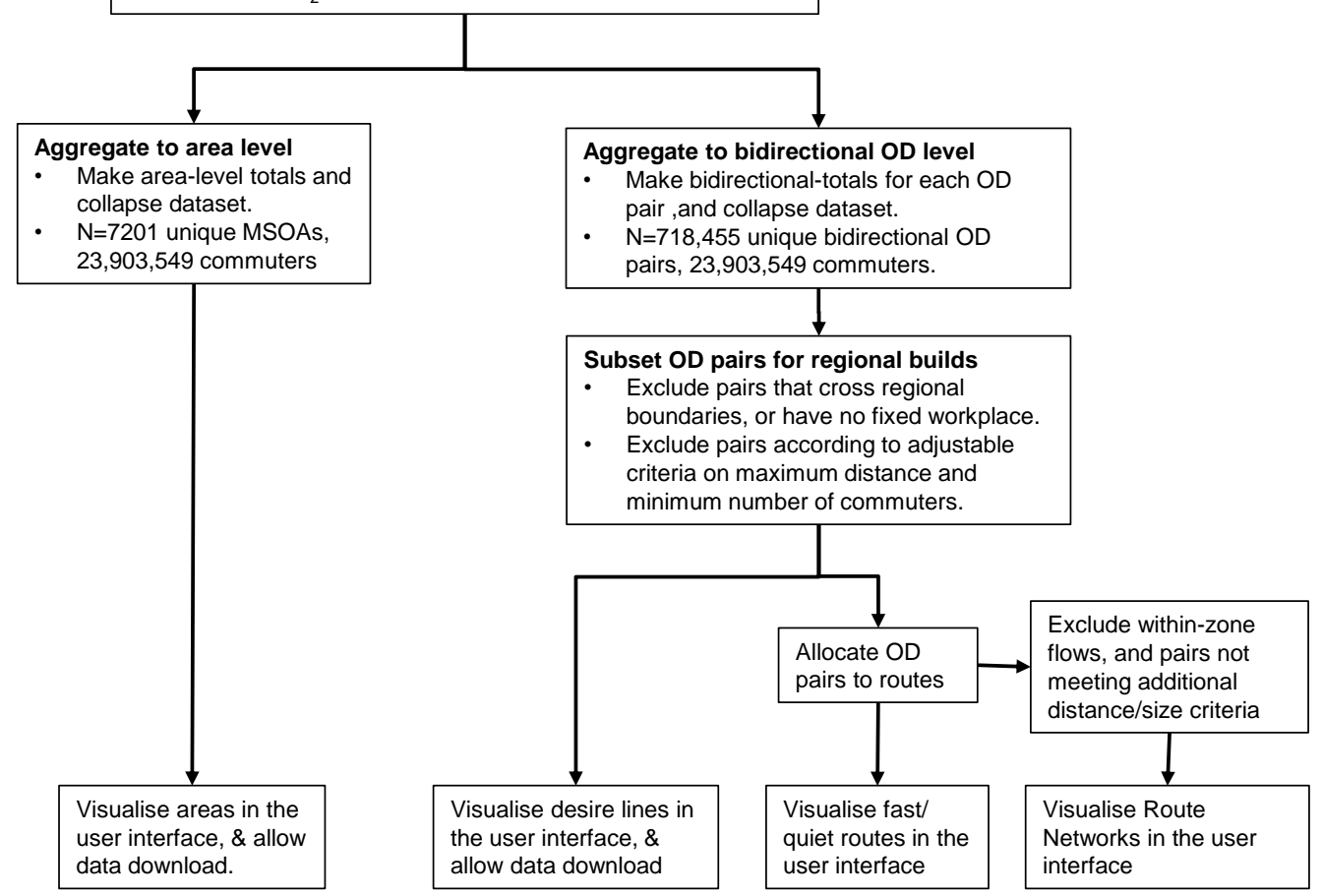

Figure 1: Flow diagram illustrating the input data and processing steps used to create the input data used by the PCT. The abbreviations are as follows: HEAT = Health Economic Assessment Tool, OD pair = origin-destination pair, MSOA = Middle-Layer Super Output Area

including terms to capture the interaction between distance and hilliness. Model fit is illustrated in Figure 2; see the Appendix for details and for the underlying equations. We also developed equations to estimate commuting mode share among groups not represented in the between-zone ('interzonal') OD data, e.g., those commuting within a specific MSOA (this is within-zone or 'intrazonal' travel), or those with no fixed workplace. This model of baseline propensity to cycle formed the basis of three of the four scenarios (Government Target, Go Dutch and Ebikes), as described in more detail in the next section. 
Table 2: Sample of the OD (origin-destination) input dataset, representing the number of people who commute from locations within and between administrative zones (MSOAs). Note 'Car' refers to people who drive as their main mode of travel per OD pair, rather than people who travel to work as a passenger in a car.

\begin{tabular}{lllllll}
\hline & & \multicolumn{5}{c}{ Number of commuters by main mode } \\
\hline Area of residence & Area of workplace & Total & Cycle & Walk & Car & Other \\
\hline E02002361 & E02002361 & 109 & 2 & 59 & 39 & 9 \\
E02002361 & E02002362 & 7 & 1 & 0 & 4 & 2 \\
E02002361 & E02002363 & 38 & 0 & 4 & 24 & 10 \\
E02002361 & E02002364 & 15 & 1 & 0 & 10 & 4 \\
E02002361 & E02002366 & 29 & 1 & 10 & 11 & 7 \\
\hline
\end{tabular}
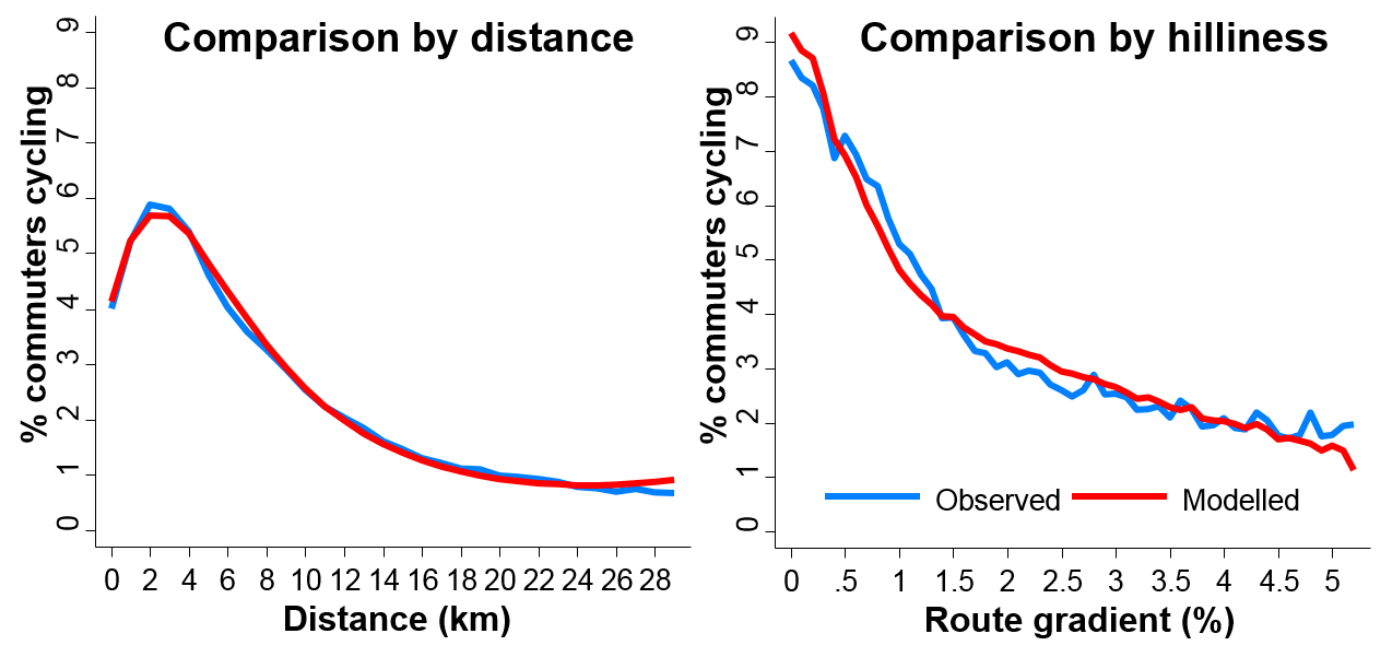

Figure 2: The relationship between distance (left) and hilliness (right) and cycling mode share based on data from the 2011 Census for England and Wales. The plots show actual (blue) vs predicted (red) prevalence of cycling to work among commuters travelling $<30 \mathrm{~km}$ to work.

\subsection{Scenarios of cycling uptake}

Four scenarios were developed to a range of explore cycling futures. These can be framed in terms of the removal of different infrastructural, cultural and technological barriers that currently prevent cycling being the natural mode of choice for trips of short to medium distances. They are not predictions of the future. They are snapshots indicating how the spatial distribution of cycling may shift as cycling grows based on current travel patterns. At a national level, the first two could be seen as shorter-term and the second two more ambitious. The choice of scenarios was informed by a government target to double the number of cycle trips and evidence from overseas about which trips could be made by cycling. Summaries of the four scenarios are as follows (see the Appendix for full details):

- Government Target. This scenario represents a doubling of the level of cycling, in line with the government's target to double the number of 'stages' (legs of a trip using a single mode) cycled by 2025 (Department for Transport 2014). Although substantial in relative terms, the rate of cycling under this scenario (rising from 3\% to 6\% of English commuters) remains low compared with countries such as the Netherlands and Denmark. This scenario was generated by adding together a) the observed number of cyclists in each OD pair in the 2011 Census, and b) the modelled number of cyclists, as estimated using the baseline propensity to cycle equations 
described in the previous section. The result is that cycling overall doubles at the national level, but at the local level this growth is not uniform, in absolute or relative terms. Areas with many short, flat trips and a below-average current rate of cycling are projected to more than double. Conversely, areas with above-average levels of cycling and many long-distance hilly commuter routes will experience less than a doubling.

- Gender Equality. This scenario illustrates the increase in cycling that would result if women were as likely as men to cycle a given trip. Specifically, the scenario sets the proportion of female cycle commuters to be equal to the current proportion of males in each OD pair. The scenario is based on the observation that in places where cycling accounts for a high proportion of personal travel, women cycle at least as much as men (Aldred et al. 2016; Pucher et al. 2010). This scenario has the greatest relative impact in areas where the rate of cycling is highly gender-unequal.

- Go Dutch. While the Government Target and Gender equality scenarios model relatively modest increases in cycle commuting, Go Dutch represents what would happen if English people were as likely as Dutch people to cycle a trip of a given distance and level of hilliness. This scenario thereby captures the proportion of commuters that would be expected to cycle if all areas of England had the same infrastructure and cycling culture as the Netherlands (but retained their hilliness and commute distance patterns). This scenario was generated by taking baseline propensity to cycle (see previous section), and applying Dutch scaling factors - parameters which increase the proportion of trips cycled above the baseline level of cycling per OD pair. These scaling factors were calculated through analysis of the British and Dutch National Travel Surveys. We parameterised the scaling factors as one fixed parameter (the main effect) plus one distance-dependent parameter (parametrised as an interaction between Dutch status and trip distance), to take into account the fact that the "Dutch multiplier" is greater for shorter trips compared to longer trips. Note that the scenario level of cycling under Go Dutch is not affected by the current level of cycling, but is instead purely a function of the distance and hilliness of each OD pair - i.e., the two characteristics that determine baseline propensity to cycle.

- Ebikes. This scenario models the additional increase in cycling that would be achieved through the widespread uptake of electric cycles ('ebikes'). This scenario is generated by taking baseline propensity to cycle, applying the Dutch scaling factors described above, and then additionally applying Ebike scaling factors. The Ebikes scenario is thus currently implemented as an extension of Go Dutch but could in future be implemented as an extension of other scenarios. The Ebike scaling factors were generated through analysis of the UK, Dutch and Swiss National Travel Surveys, in which we estimated how much more likely it was that a given commute trip would be cycled by Ebike owners versus cyclists in general. We parameterised the scaling factors as varying according to trip distance and according to hilliness, by fitting interaction terms between these two characteristics and ebike ownership (Equation 1B). We did this to take account of the fact that electric cycles enable longer journeys and reduce the barrier of hills

Additional scenarios could be developed (see Discussion). If deployed in other settings, the PCT will likely benefit from scenarios that relate to both the current policy context and long-term aspirations.

\subsection{Estimation of health and carbon impacts}

Because the cost effectiveness of cycling investments are influenced by wider social impacts, estimated health economic and emissions impacts are presented in the PCT.

An approach based on the World Health Organization's Health Economic Assessment Tool (HEAT) was used to estimate the number of premature deaths avoided due to increased physical activity (Kahlmeier et al. 2014). To allow for the fact that cycling would in some cases replace walking trips, HEAT estimates of the increase in premature deaths due to the reduction in walking were also included. The 
change in walking was estimated based on the assumption that, within a given OD pair, all modes were equally likely to be replaced by cycling. Thus all the non-cycling modes shown in Table 2 experienced the same relative decrease.

Trip duration was estimated as a function of the 'fast' route distance and average speed. For walking and cycling we applied the standard HEAT approach (applied to a 'stable' future year in which full non discounted benefits are realised). Ebikes are not specifically covered in HEAT Cycling but enable faster travel and require less energy from the rider than traditional bikes. Thus we estimated new speeds and intensity values for this mode, giving a smaller benefit for every minute spent using Ebikes than conventional cycles. For more details see the Appendix.

The risk of death varies by gender and increases rapidly with age. This was accounted for using age and sex-specific mortality rates for each local authority in England. For the baseline and Government Target scenario the age distribution of cyclists recorded in the 2011 Census was used. New cyclists under Go Dutch and Ebikes were assumed to have the age-gender profile of commuter cyclists in the Netherlands. The inclusion of age specific parameters and mode shift from walking shows how the HEAT approach can generate nuanced health impact estimates using publicly available data.

The net change in the number of deaths avoided for each OD pair was estimated as the number of deaths avoided due to cycle commuting minus the number of additional deaths due to reduced walking. Note that this approach means that for some OD pairs where walking made up a high proportion of trips, additional deaths were incurred. The monetary value of the mortality impact was calculated by drawing on the standard 'value of a statistical life' used by the Department for Transport.

We also estimated the reduction in transport carbon emissions resulting from decreased car driving in each scenario. This again relied on the assumption that all modes were equally likely to be replaced by cycling. The average $\mathrm{CO}^{2}$-equivalent emission per kilometre of car driving was taken as $0.186 \mathrm{~kg}$, the 2015 value of an 'average' car (DEFRA 2015).

\subsection{Visualisation, route allocation and network generation}

The data analysis and preparation stages described in the previous sections were conducted using the national OD dataset for England as a whole. By contrast, the stages described in this section were conducted using a region-by-region approach. Transport decisions tend to be made at local and regional levels (Gaffron 2003), hence the decision to display results on a per region basis.

Figure 3 shows the output: 'desire lines' lines with attributes for each OD pair aggregated in both directions (Chan and Suja 2003; Tobler 1987), and visualised as centroid to centroid 'flows' (Rae 2009; Wood et al. 2010).

Desire lines allocated to the route network are illustrated in Figure 4. This shows two route options: the 'fast' route, which represents an estimate of the route taken by cyclists to minimise travel time and the 'quiet' route that preferentially selects smaller, quieter roads and off road paths.

Routes generated by CycleStreets.net do not necessarily represent the paths that cyclists currently take; route choice models based on GPS data have been developed for this purpose (Broach et al. 2012; Ehrgott et al. 2012). Of the available routes (see cyclestreets.net/journey/help for more information), the 'fastest' option was used. This decision was informed by recommendations from (CROW 2007), building on evidence of cyclists' preference direct routes.

The spatial distribution of cycling potential can be explored interactively by selecting the 'top n' routes with the highest estimated cycling demand (see the slider entitled "N. Lines (most cycled)" in Figures 3 and 4). Information about the aggregate cycling potential on the road network is shown in the Route Network layer. Because the layer is the result of aggregating overlapping 'fast' routes, and summing the level of cycling for each scenario (see Figure 5), it relates to the capacity that infrastructure may need to handle. Cycling along Otley Road (highlighted in Figure 5), under the Go Dutch scenario, rises from 73 to 296 commuters along a single route, but from 546 to 1780 in the Route Network. Note that more confidence can be placed in the relative rather than the absolute size of 


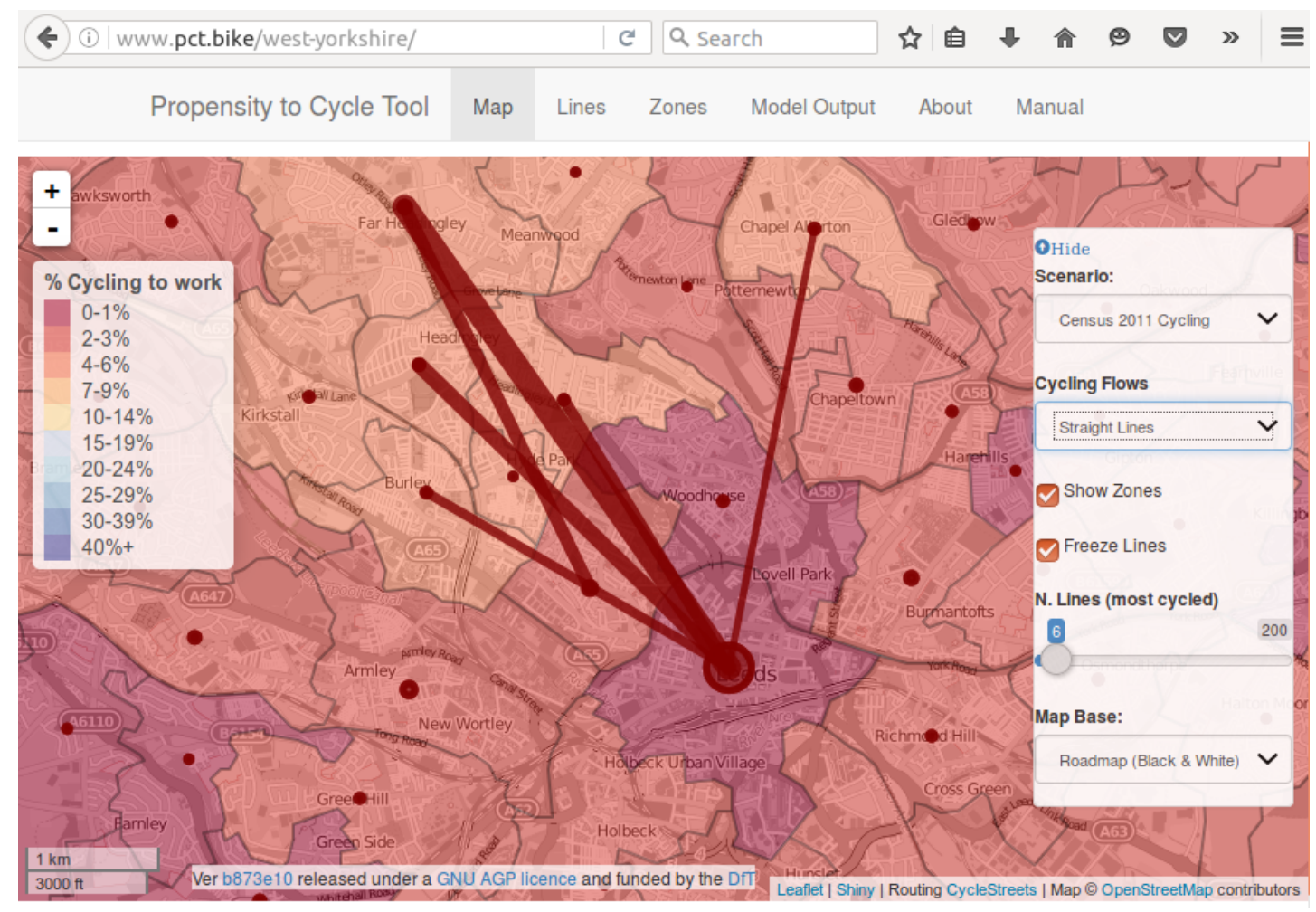

Figure 3: Overview of the PCT map interface, showing area and OD-level data. The zone colour represents the number of residents who cycle to work. The lines represent the top 6 most cycled commuter routes in Leeds, with width proportional to the total number of cycle trips. Population-weighted centroids are represented by circles, the diameter of which is proportional to the rate of within-zone cycling.

these numbers: the Route Network layer excludes within-zone commuters, commuters with no fixed workplace, and commuters working in a different region (see Figure 1). Route Network values also omit routes due to the adjustable selection criteria: maximum distance and minimum total numbers of all-mode commuters per OD pair. At the time of writing these were set to $20 \mathrm{~km}$ Euclidean distance and 10 commuters respectively. Nationally, the Route Network layer under these settings accounts for around two thirds of cycle commuters.

\section{Outputs of the Propensity to Cycle Tool}

This section describes and illustrates some outputs from the PCT, alongside discussion of how these outputs could be used in transport planning. Note that some details of the graphics in the online version may evolve as the PCT develops.

\subsection{Model output tabs}

Tabs are panels within the PCT that reveal new information when clicked (see the top of Figure 3). Of these, the first four provide region-specific information:

- Map: This interactive map is the main component of the PCT, and is the default tab presented to users. It shows cycling potential at area, desire-line, route and route network levels under different scenarios of change, as described throughout this paper. 'Popups' appear when zones, desire lines or segments on the Route Network are clicked, presenting quantitative information about the selected element. 


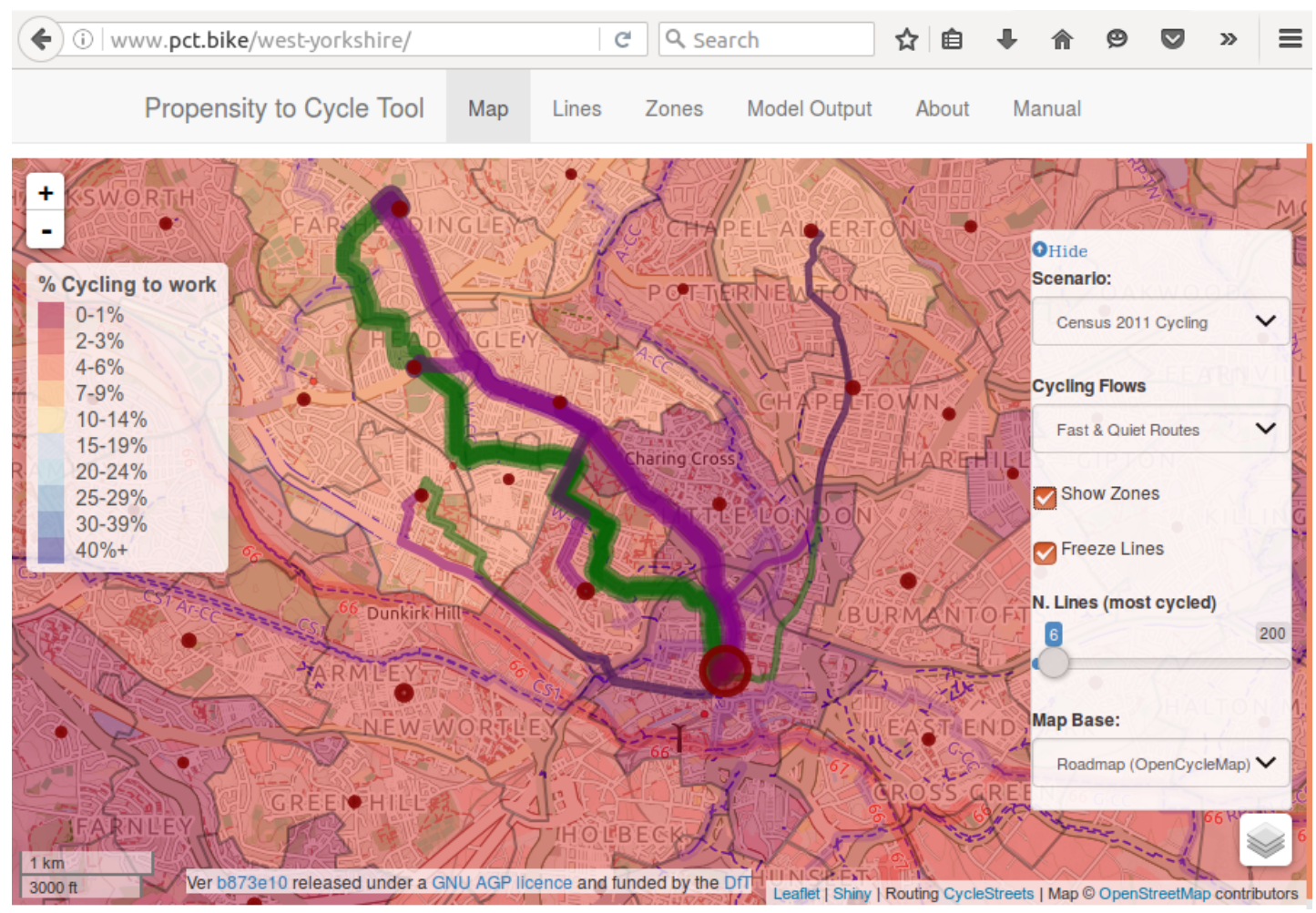

Figure 4: Illustration of desire lines shown in Figure 3 after they have been allocated to the road network by CycleStreets.net. Purple and green lines represent 'fastest' and 'quietest' routes generated by CycleStreets.net, respectively.
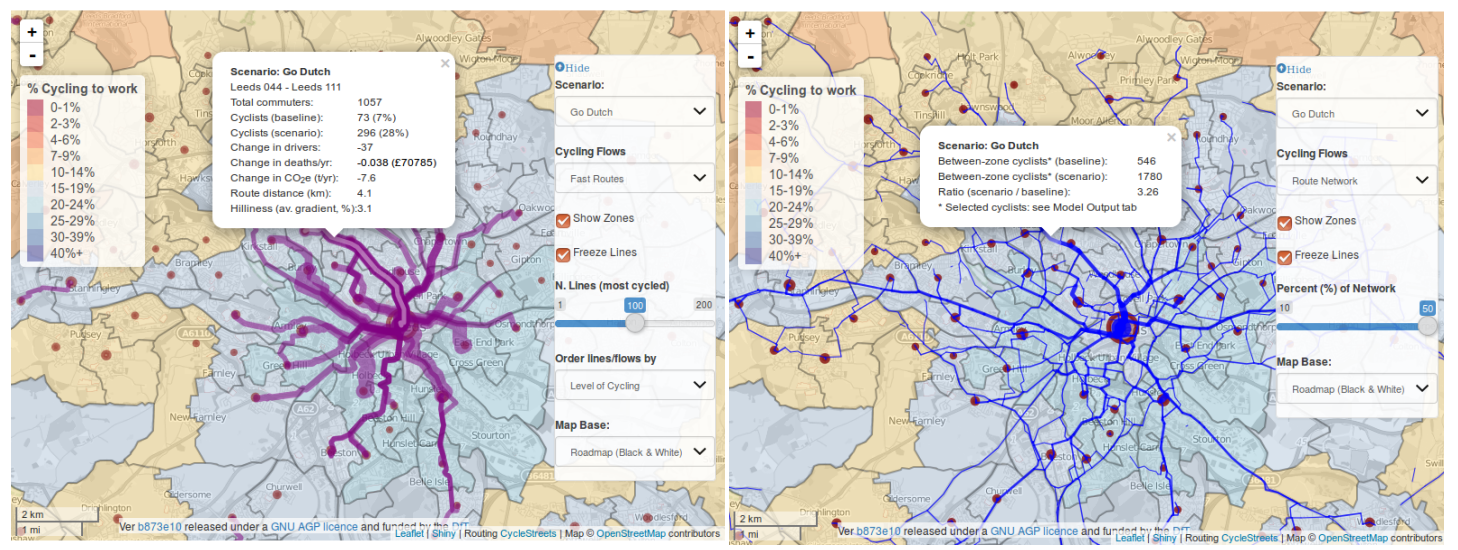

Figure 5: Illustration of Fast Routes map layer (left) compared with Route Network layer (right). The Route Network was was produced by aggregating all overlapping lines in the Fast Routes layer using the stplanr R package. 

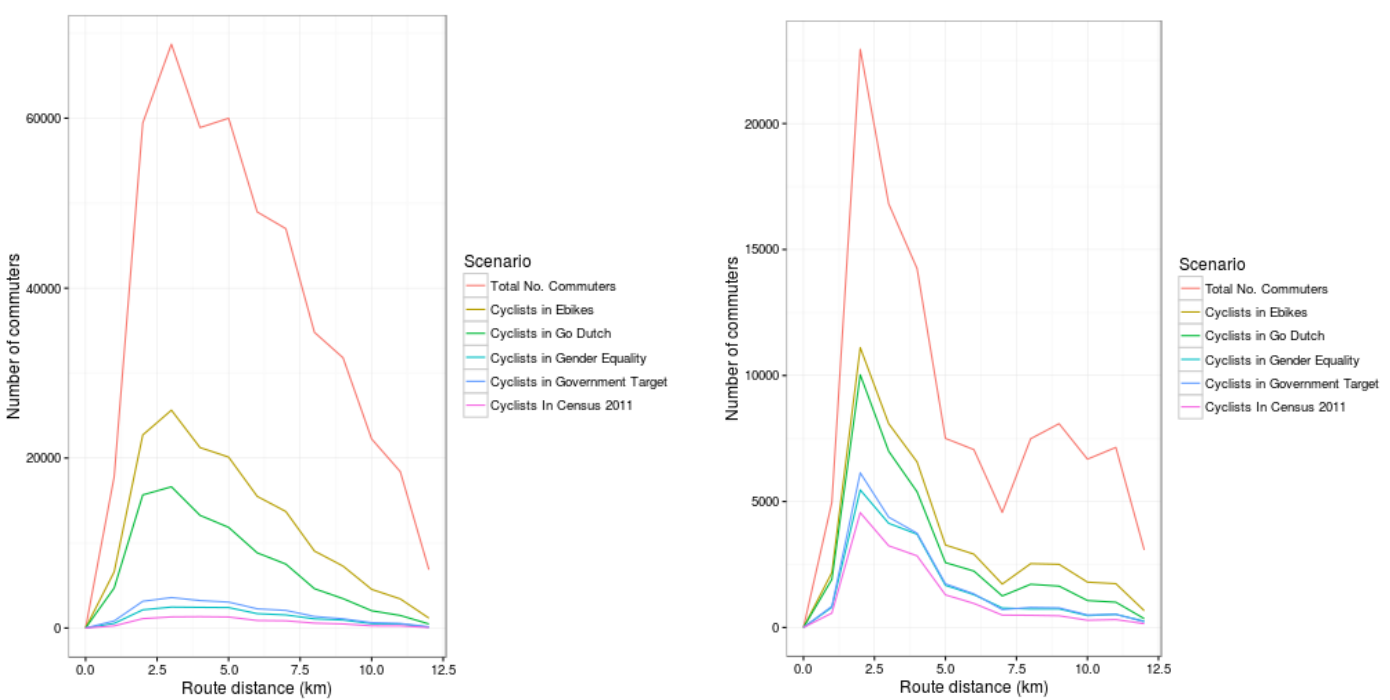

Figure 6: Number of between-zone commuters in West Yorkshire (left) and Oxfordshire (right) by distance, currently and under 4 scenarios of change.

- Lines: When lines are displayed on the interactive map, this tab provides raw data on a sample of the variables as a table at the OD pair level.

- Areas: This tab is the equivalent of the 'Lines' tab, but with data at the area level.

- Model output: This tab provides key statistics, diagnostic plots and model results for each region. The document is produced by a 'dynamic document' which runs embedded code for each regional dataset. Diagnostic plots include the distribution of cycling by trip distance under each scenario (see Figure 6), providing insight into local travel patterns and how they relate to cycling potential in the region overall.

\subsection{Trip distance distributions}

Figure 6 shows how the proportion of trips made by cycling varies as a function of distance in two regions currently, and under the PCT's four scenarios of change. The frequency of all mode trips by distance band (the red lines) illustrates the two regions have different spatial structures. Oxfordshire has a high proportion short (under $5 \mathrm{~km}$ ) trips, helping to explain the relatively high level of cycling there. West Yorkshire (Figure 6, left), by contrast, has a higher proportion of longer distance commutes and a lower level of cycling than Oxford. Note that under Go Dutch and Ebikes scenarios, regional differences in the rate of cycling diminish, however, illustrating that these scenarios are not influenced by the current level of cycling.

\subsection{The shifting spatial distribution of cycling and associated impacts}

The spatial distribution of cycling potential differs markedly between scenarios, as illustrated in Figure 7 for the city of Leeds, West Yorkshire. The top 50 OD pairs in Leeds under Government Target are strongly influenced by the current distribution of cycling trips, concentrated in the North of the city (see Figure 3 for comparison with the baseline). Under the Go Dutch scenario, by contrast, the pattern of cycling shifts substantially to the South. The cycling patterns under the Go Dutch scenario are more representative of short-distance trips across the city overall. In both cases the desire lines are focussed on Leeds city centre: the region has a mono-centric regional economy, making commute trips beyond around $5 \mathrm{~km}$ from the centre much less likely to be made by cycling. 


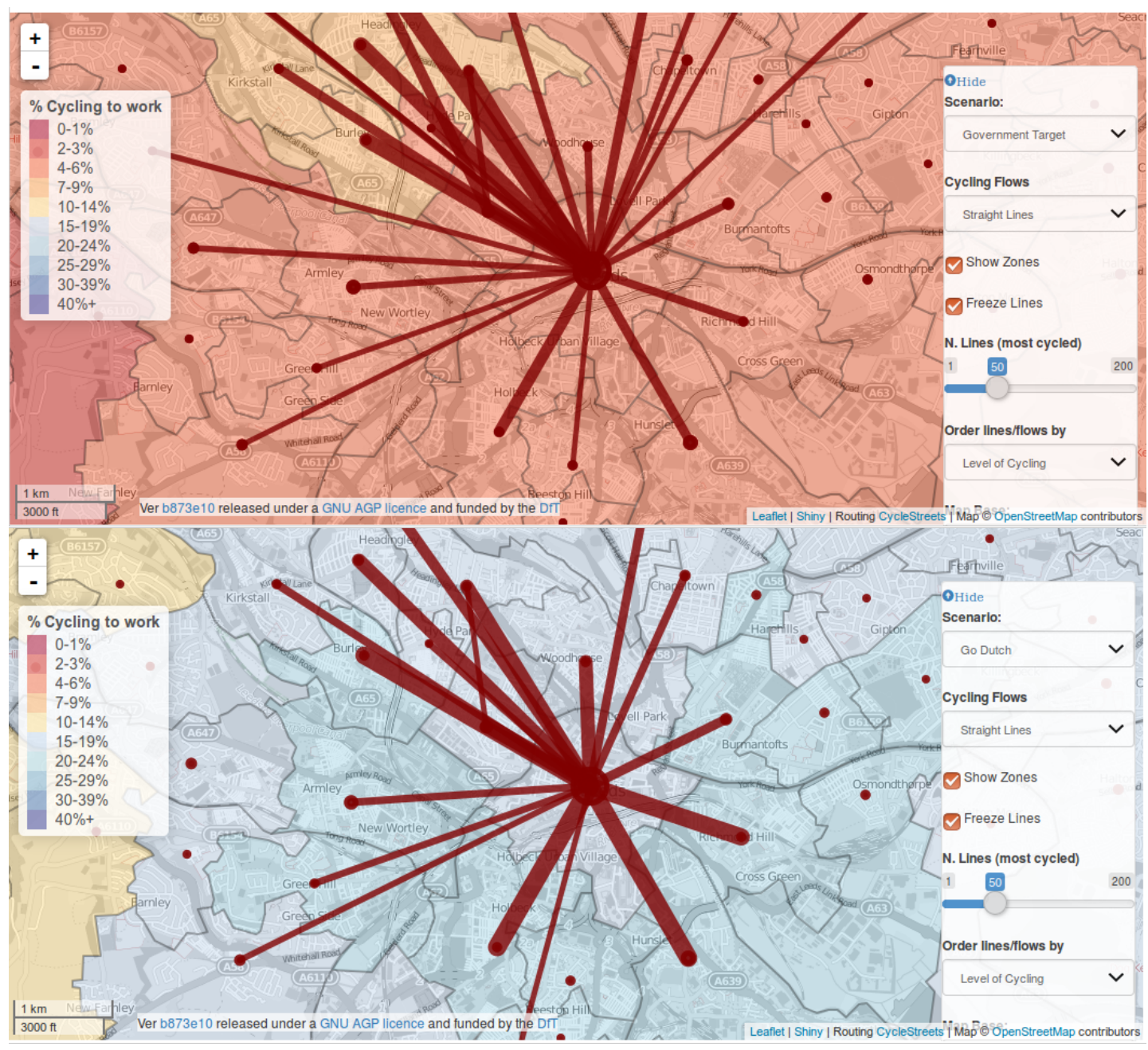

Figure 7: Model output illustrating the top 6 most cycled OD pairs in Leeds under the Government Target and Go Dutch scenarios.

The same scenario is illustrated in Figure 8 with the Route Network layer. This shows how the number of commuter cyclist using different road segments could be expected to change. The number using York Road, highlighted in Figure 8, for example more than triples (from 88 to 318 ) under Government Target and increases more than 10 fold under Go Dutch (from 88 to 1426). This contrasts with Otley Road (highlighted in Figure 5), which 'only' triples under the Go Dutch scenario. These outputs suggest that the geographical distribution of cycling may shift if the proportion of trips cycled increases in the city. The results also suggest that cycle paths built to help achieve ambitious targets, as represented by the Go Dutch scenario, should be of sufficient width to accommodate the estimated flows.

Another output that can be highly policy relevant is the difference between 'fast' and 'quiet' routes. Figure 9 illustrates this by showing the Fast \& Quiet Routes layer in Manchester with the highest cycling potential under the Government Target scenario. The 'quiet' route is longer: $2.8 \mathrm{~km}$ (as shown by clicking on the line) compared with the more direct fast route which is $2.3 \mathrm{~km}$. However, the 'fast' route may not currently be attractive for cycling as it passes along a busy dual carriage way. The Euclidean distance associated with this OD pair is $1.6 \mathrm{~km}$ (this can be seen by clicking on a line illustrated from the 'Straight Lines' layer in the PCT's interface), resulting in 'circuity' (see Iacono et al. 2008), values of 1.6 and 1.4 for 'quiet' and 'fast' routes respectively. 


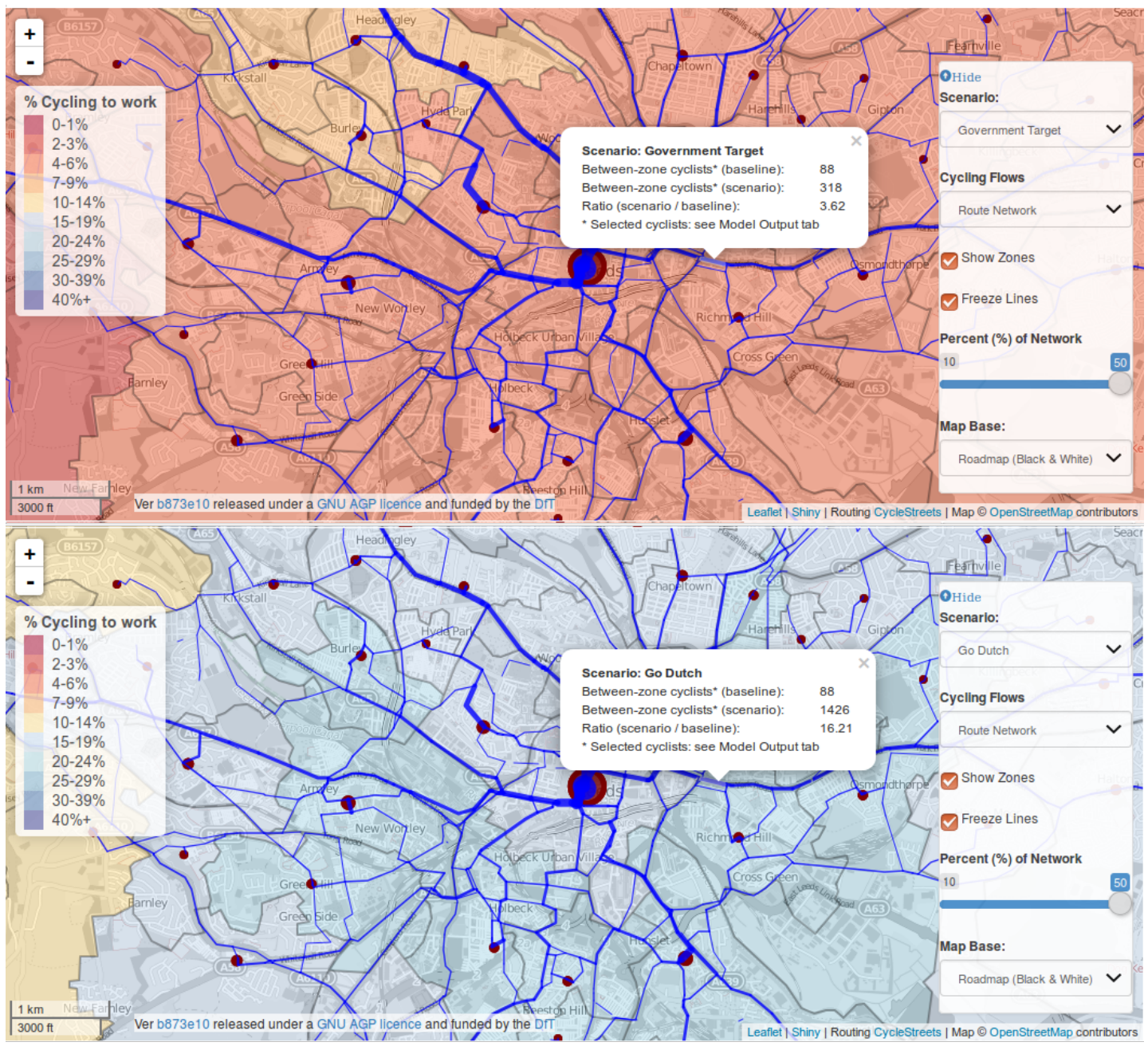

Figure 8: The Route Network layer illustrating the shifting spatial distribution of cycling flows in Leeds under Government Target (top) and Go Dutch (bottom) scenarios.

Dutch guidance suggests that circuity values "for cycle provision should be 1.2" (CROW 2007). Evidence indicates that women and older people have a greater preference for off-road and shorter routes (Garrard et al. 2008; Woodcock et al. 2016). This suggests the 'fast route' option, if built to a high standard, may be favourable from an equity perspective in this context.

Three basemap options are worth highlighting in addition to the grey default basemap. These were selected to provide insight into how the geographical distribution of latent demand for cycling relates to current cycle infrastructure and socio-demographics: 'OpenCycleMap' indicates where cycle provision is (and is not) currently; 'Index of Deprivation' illustrates the spatial distribution of social inequalities; and the 'Satellite' basemap can help identify opportunities for re-allocating space away from roads and other land uses for cycle and walking paths by providing visual information on road widths and land uses along desire lines. The 'Satellite' basemap option is illustrated in Figure 10, which shows a section of Trinity Way (as it crosses the River Irwell). This shows there are 4 lanes of traffic, a central paved area and wide pavements on both sides of the road, suggesting there may be space for a cycle path, especially if road space were re-allocated away from motorised traffic.

Another feature of the user interface worth highlighting is addition of a dropdown menu to enable the 'top n' routes to be selected not only based on the level of cycling, but also based on estimated health and carbon impacts, under each scenario. The reason for this addition was the finding that health benefits do not always rise in simply in proportion to the number of people cycling, e.g., longer trips 


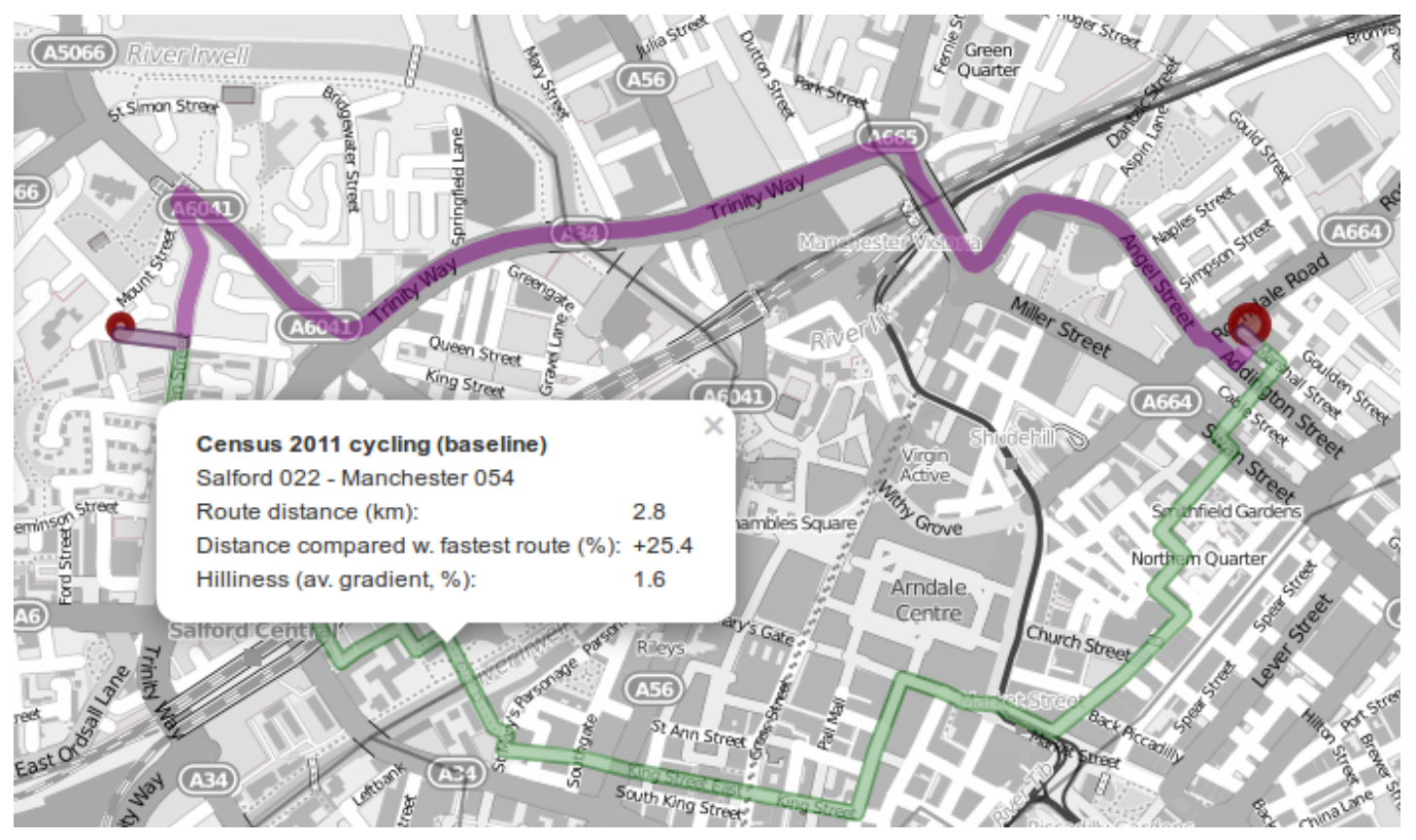

Figure 9: Close-up of a 'fast' and 'quiet' route in the PCT under the Government Target scenario in Manchester. This provides an indication of the local 'quietness diversion factor.'

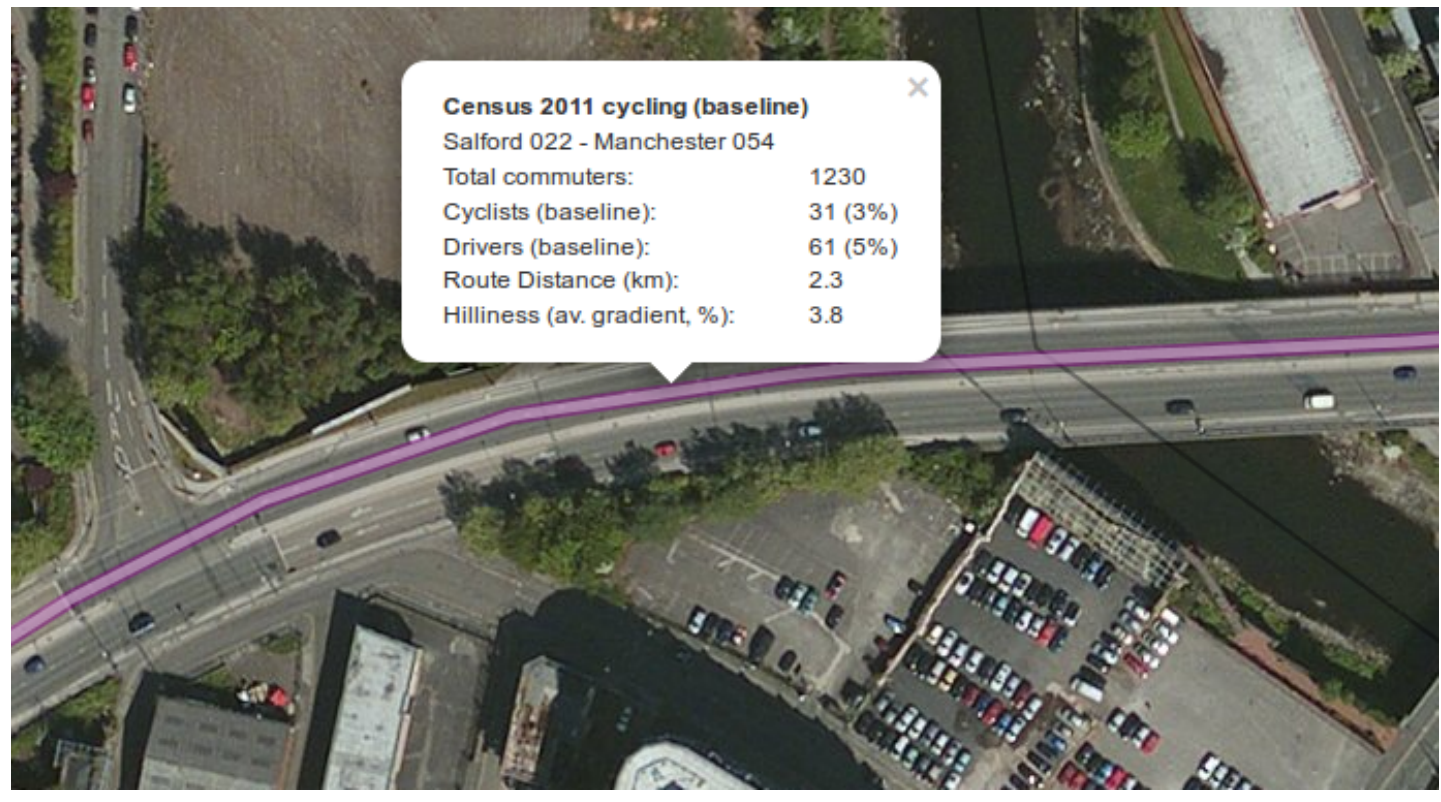

Figure 10: Zoomed-in section of Trinity way (see Figure 9) using the Satellite basemap to show road width and the number of lanes allocated to motorised traffic. 
lead to a greater health benefit than short ones do, and this is now represented by shifting distribution of lines when the "HEAT Value" option is selected from the "Order lines/flows by" dropdown menu (this menu only appears when lines are shown and a scenario other than the Census 2011 is selected).

This feature is illustrated in Figure 5, economic value of health benefits reported for the $4.1 \mathrm{~km}$ route in Figure 5 is estimated to be $£ 70785$. When health benefits are the main criteria for policy evaluation, OD pairs with low current rates of walking would be favoured for intervention. When emissions are the main criteria, OD pairs with a high baseline level of car use are also favoured. The exploration of these considerations is facilitated in the PCT by allowing users to select the top routes ranked by health and carbon benefits.

\section{Discussion}

We have outlined a method for modelling and visualising the spatial distribution of cycling flows, currently and under various scenarios of 'cycling futures'. Inspired by previous approaches to estimating cycling potential (Larsen et al. 2013; Zhang et al. 2014) and by online, interactive planning support systems (PSS) (Pettit et al. 2013), the PCT tackles the issue of how to generate an evidence base to decide where new cycle paths and other localised pro-cycling interventions should be prioritised. By showing potential health-related benefits the tool provides various metrics for transport planners, going beyond the number of additional trips. Illustrative uses of the PCT demonstrated the potential utility of the tool, for example by showing settings in which the spatial distribution of cycling demand is likely to shift as cycling grows.

In addition to creating an evidence base for planning specific routes and area-based interventions, the long-term Go Dutch and Ebikes scenarios could be used for envisioning different transport futures (Hickman et al. 2011). The PCT could also: help translate national targets into local aspirations (as illustrated by the Government Target scenario); inform local targets (e.g., by indicating what the potential in one region is relative to neighbouring regions); support business cases (by showing that there is high cycling potential along proposed routes); and help plan for cycle capacity along the route network via the network analysis layer. Ongoing case study work with stakeholders will be needed to establish and develop these uses. Future developments will be facilitated by the open source code-base underlying the PCT (see github.com/npct) (Lima et al. 2014).

As with any modelling tool, the approach presented in this paper has limitations: the reliance on Census origin-destination (OD) data from 2011 means that the results are limited to commuting and may not encapsulate recent shifts in travel behaviour, and the user interface is constrained to a few, discrete, scenarios. These limitations suggest directions for future work, most notably the use of new sources of OD data.

There is often a tension between transparency and complexity in the design of tools for transport planning. Excessive complexity can result in tools that are 'black boxes' (Saujot et al. 2016). In a context of limited time, expertise, and resources, Saujot et al. caution against investing in ever more complex models. Instead, they suggest models should be more user focussed. The PCT's open source, freely available nature will, we believe, facilitate the future development of the PCT organically to meet the needs of its various users. To encourage others to use the outputs of the PCT project, we make the data underlying the online map available to download (via the Zones and Lines tabs in the tool's online interface). We envision stakeholders in local government modifying scenarios for their own purposes, and that academics in relevant fields may add new features and develop new use cases of the PCT. Such enhancements could include:

- Additional scenarios to illustrate a wider range of 'cycling futures', including medium-term and local targets.

- Use of individual level data to estimate cycling potential and impacts. The use of synthetic 'spatial microdata, for example, could enable specification of scenarios and analysis of outcomes by a much wider range of predictors (Lovelace et al. 2014). 
- Additional purposes of trips in the model. An 'education layer' would enable prioritisation of 'safe routes to school', building on methods analysing 'school commute' data (Singleton 2014). Other data sources to include more trip types include mobile telephone providers (Alexander et al. 2015) and outputs from transport models.

- Deployment of the PCT for new cities, regions or countries. This will depend on the availability of appropriate OD data, perhaps from sources mentioned in the previous point, and routing services that can estimate cyclable routes based on globally available data, e.g., using the function route_graphhopper from stplanr package. Such work could also facilitate international comparisons of cycling potential.

Transport planning is a complex and contested field (Banister 2008). When it comes to sustainable mobility, policy, politics, leadership and vision are key ingredients that computer models alone cannot supply (Melia 2015). The approach described here can, however, assist in this wider context by providing new tools for exploring the evidence at high geographical resolution and envisioning transformational change in travel behaviours.

By providing transport authorities, campaign groups and the public with access to the same evidence base, we hypothesise that tools such as the PCT can encourage informed and rigorous debate, as advocated by (Golub et al. 2013). In conclusion, the PCT provides an accessible evidence base to inform the question of where to prioritise interventions for active travel and raises more fundamental questions about how models should be used in transport planning.

\section{Author contribution statement}

The PCT was built as a collaborative effort. The Principal Investigator of the project was James Woodcock, and the initial concept for the project came from James Woodcock and Robin Lovelace in response to a call from the Department of Transport. Anna Goodman led the creation of the model underlying the PCT, and the generation of estimates of cycling levels, health gains and carbon impacts in each scenario. James Woodcock and Anna Goodman led the development of the methods for calculating health impacts. James Woodcock, Robin Lovelace, Anna Goodman, and Rachel Aldred contributed to the development of the cycling uptake rules. Robin Lovelace led the processing of these modelled estimates for spatial visualisation in the online tool and coordinated the development of the online tool. Rachel Aldred led the coordination of policy implementation and collection of practitioner feedback. Ali Abbas and Nikolai Berkoff led on the user interface, with contributions from all authors. Nikolai Berkoff led the deployment of the PCT on a public facing server. Anna Goodman led the writing of the Appendix. Robin Lovelace led the writing of this manuscript, with input from all authors.

\section{Acknowledgements}

We would like to thank the following people for comments on earlier versions of the manuscript and the development of the PCT: Roger Geffen (Cycling UK), Tom Gutowski (Sustrans), Helen Bowkett (Welsh Government), John Parkin (University of the West of England), Nikée Groot and Phil Tate. Thanks to Simon Nutall and Martin Lucas-Smith for access to and instructions on the use of the CycleStreets.net API. Thanks to Barry Rowlingson from the University of Lancaster for developing functionality in the stplanr package that enabled the creation of the Route Network layer. We are grateful to Matthew Tranter at DfT for merging additional geographic data into the UK National Travel Survey, and to Eva Heinen, Rick Prins and Thomas Götschi for their help in analysing Dutch and Swiss Travel Survey data. Thanks to Alvaro Ullrich for contributions to the code. Thanks to developers of open source software we have been able to make the PCT free and open to the world. We would also like to thank Brook Lyndhurst for assistance with the user testing, and all participants in the user test- 
ing sessions. We would also like to thank Shane Snow and other staff at the DfT for specifying the project's aims and providing feedback on early versions of the tool.

\section{Funding}

The work presented was funded by the Department for Transport (contract no. RM5019SO7766: "Provision of Research Programme into Cycling: Propensity to Cycle"), with contract facilitation and project management by Brook Lyndhurst in Phase 1, and by Atkins in Phase 2. Robin Lovelace's contribution was supported by the Consumer Data Research Centre (ESRC grant number ES/L011891/1). James Woodcock's contribution was supported by an MRC Population Health Scientist Fellowship. James Woodcock's and Ali Abbas' contributions were supported by the Centre for Diet and Activity Research (CEDAR), a UKCRC Public Health Research Centre of Excellence funded by the British Heart Foundation, Cancer Research UK, Economic and Social Research Council, Medical Research Council, the National Institute for Health Research (NIHR), and the Wellcome Trust. Anna Goodman's contribution was supported by an NIHR postdoctoral fellowship. The views reported in this paper are those of the authors and do not necessarily represent those of the DfT, Brook Lyndhurst, Atkins the NIHR, the NHS or the Department for Health. 


\section{References}

Aldred, R., J. Woodcock, and A. Goodman. 2016. Does More Cycling Mean More Diversity in Cycling? Transport Reviews, 36(1):28-44. ISSN 0144-1647. doi: 10.1080/01441647.2015.1014451. URL http://dx.doi.org/10.1080/01441647.2015.1014451.

Alexander, L., S. Jiang, M. Murga, and M. C. Gonz. 2015. Validation of origin-destination trips by purpose and time of day inferred from mobile phone data. Transportation Research Part B: Methodological, pp. 1-20. ISSN 0968-090X. doi: 10.1016/j.trc.2015.02.018. URL http://dx.doi.org/10. 1016/j.trc.2015.02.018.

Aultman-Hall, L., F. Hall, and B. Baetz. 1997. Analysis of bicycle commuter routes using geographic information systems: implications for bicycle planning. Transportation Research Record: Journal of the Transportation Research Board, 1578(1578):102-110. ISSN 0361-1981. doi: 10.3141/157813.

Banister, D. 2008. The sustainable mobility paradigm. Transport Policy, 15(2):73-80. ISSN 0967070X. doi: DOI:10.1016/j.tranpol.2007.10.005. URL http://www.sciencedirect.com/science/ article/B6VGG-4R5G81G-1/2/9128e2cf327c3e81c4a8dc41d8e7a93e.

Borning, A., P. Waddell, and R. Förster. 2008. UrbanSim: Using simulation to inform public deliberation and decision-making. In Digital government, pp. 439-464. Springer. URL http: //link.springer.com/chapter/10.1007/978-0-387-71611-4_22.

Broach, J., J. Dill, and J. Gliebe. 2012. Where do cyclists ride? A route choice model developed with revealed preference GPS data. Transportation Research Part A: Policy and Practice, 46(10):17301740. ISSN 09658564. doi: 10.1016/j.tra.2012.07.005. URL http://dx.doi.org/10.1016/j.tra. 2012.07.005.

Buehler, R. and J. Dill. 2016. Bikeway Networks: A Review of Effects on Cycling. Transport Reviews, 36(1):9-27. ISSN 0144-1647. doi: 10.1080/01441647.2015.1069908. URL http://dx.doi.org/ $10.1080 / 01441647.2015 .1069908$.

Chan, W.-T. and T. Suja. 2003. A Multi-Criteria Approach in Designing Bicycle Tracks. In Map Asia Conference.

Chatterjee, K., H. Sherwin, and J. Jain. 2013. Triggers for changes in cycling: the role of life events and modifications to the external environment. Journal of Transport Geography, 30:183-193. ISSN 0966-6923. doi: 10.1016/j.jtrangeo.2013.02.007. URL http://www.sciencedirect.com/science/ article/pii/S0966692313000215.

CROW. 2007. Design manual for bicycle traffic. Amsterdam: Kennisplatform. URL http://www. crow.nl/publicaties/design-manual-for-bicycle-traffic\#tab:tab-Inhoudsopgave.

De Nazelle, A., M. J. Nieuwenhuijsen, J. M. Antó, M. Brauer, D. Briggs, C. Braun-Fahrlander, N. Cavill, A. R. Cooper, H. Desqueyroux, and S. Fruin. 2011. Improving health through policies that promote active travel: a review of evidence to support integrated health impact assessment. Environment international, 37(4):766-777. ISSN 0160-4120.

DEFRA. 2015. DEFRA Carbon Factors: UK Government conversion factors for Company Reporting, 2015, V2.0. URL http://www.ukconversionfactorscarbonsmart.co.uk/.

Department for Transport. 2014. Cycling Delivery Plan: Draft. October. Department for Transport. URL https://www.gov.uk/government/uploads/system/uploads/attachment_data/file/364791/ 141015_Cycling_Delivery_Plan.pdf.

Department for Transport. 2015. Response to the consultation on the draft Cycling Delivery Plan. Technical report, Department for Transport, London. URL https://www.gov.uk/government/ uploads/system/uploads/attachment_data/file/417706/consultation-response.pdf.

Ehrgott, M., J. Y. T. Wang, A. Raith, and C. van Houtte. 2012. A bi-objective cyclist route choice model. Transportation Research Part A: Policy and Practice, 46(4):652-663. ISSN 09658564. doi: 10.1016/j.tra.2011.11.015. URL http://linkinghub.elsevier.com/retrieve/pii/ S0965856411001844http://www.sciencedirect.com/science/article/pii/S0965856411001844. 
Fishman, E. 2016. Cycling as transport. Transport Reviews, 36(1):1-8. ISSN 0144-1647, 14645327. doi: 10.1080/01441647.2015.1114271. URL http://www.tandfonline.com/doi/full/10. 1080/01441647.2015.1114271.

Gaffron, P. 2003. The implementation of walking and cycling policies in British local authorities. Transport Policy, 10(3):235-244. ISSN 0967070X. doi: 10.1016/S0967-070X(03)00024-6. URL http://linkinghub.elsevier.com/retrieve/pii/S0967070X03000246.

Garrard, J., G. Rose, and S. K. Lo. 2008. Promoting transportation cycling for women: The role of bicycle infrastructure. Preventive Medicine, 46(1):55-59. ISSN 0091-7435. doi: 10.1016/j.ypmed.2007.07.010. URL http://www.sciencedirect.com/science/article/pii/ S0091743507003039.

Golub, A., G. Robinson, and B. Nee. 2013. Making accessibility analyses accessible: A tool to facilitate the public review of the effects of regional transportation plans on accessibility. Journal of Transport and Land Use, 6(3):17-28. ISSN 1938-7849. doi: 10.5198/jtlu.v6i3.352. URL https://jtlu.org/ index.php/jtlu/article/view/352.

Haklay, M., A. Singleton, and C. Parker. 2008. Web Mapping 2.0: The Neogeography of the GeoWeb. Geography Compass, 2(6):2011-2039. ISSN 17498198, 17498198. doi: 10.1111/j.17498198.2008.00167.x. URL http://doi.wiley.com/10.1111/j.1749-8198.2008.00167.x.

Han, J. and Y. Hayashi. 2008. Assessment of private car stock and its environmental impacts in China from 2000 to 2020. Transportation Research Part D: Transport and Environment, 13(7):471-478. ISSN 1361-9209.

Heath, G. W., R. C. Brownson, J. Kruger, R. Miles, K. E. Powell, L. T. Ramsey, and T. F. o. C. P. Services. 2006. The effectiveness of urban design and land use and transport policies and practices to increase physical activity: a systematic review. Journal of Physical Activity \& Health, 3:S55. ISSN 1543-3080.

Heinen, E., J. Panter, R. Mackett, and D. Ogilvie. 2015. Changes in mode of travel to work: a natural experimental study of new transport infrastructure. International Journal of Behavioral Nutrition and Physical Activity, 12(1):81. ISSN 1479-5868. doi: 10.1186/s12966-015-0239-8. URL http: //www.ijbnpa.org/content/12/1/81.

Hickman, R., O. Ashiru, and D. Banister. 2011. Transitions to low carbon transport futures: strategic conversations from London and Delhi. Journal of Transport Geography, 19(6):1553-1562. ISSN 0966-6923. doi: 10.1016/j.jtrangeo.2011.03.013. URL http://www.sciencedirect.com/science/ article/pii/S096669231100130X.

Iacono, M., K. Krizek, and A. El-Geneidy. 2008. Access to Destinations: How Close is Close Enough? Estimating Accurate Distance Decay Functions for Multiple Modes and Different Purposes. p. 76.

Kahila-Tani, M., A. Broberg, M. Kyttä, and T. Tyger. 2016. Let the Citizens Map-Public Participation GIS as a Planning Support System in the Helsinki Master Plan Process. Planning Practice \& Research, 31(2):195-214. ISSN 0269-7459. doi: 10.1080/02697459.2015.1104203. URL http://dx.doi.org/10.1080/02697459.2015.1104203.

Kahlmeier, S., P. Kelly, C. Foster, T. Götschi, N. Cavill, H. Dinsdale, J. Woodcock, C. Schweizer, H. Rutter, and C. Lieb. 2014. Health economic assessment tools (HEAT) for walking and for cycling, Methods and User Guide. World Health Organization Regional Office for Europe, Copenhagen, Denmark, p. 2014.

Klosterman, R. E. 1999. The What If? Collaborative Planning Support System. Environment and Planning B: Planning and Design, 26(3):393-408. ISSN 0265-8135, 1472-3417. doi: 10.1068/b260393. URL http://epb.sagepub.com/content/26/3/393.

Komanoff, C. 2004. Bicycling. In C. J. Cleveland, ed., Encyclopedia of Energy, pp. 141-150. New York: Elsevier. ISBN 978-0-12-176480-7. URL http://www.sciencedirect.com/science/article/ B7GGD-4CM9GC0-1K/2/dcdc8c3769ea30a3dc68c2fbbfc5afb8.

Kuzmyak, J. R., J. Walters, M. Bradley, and K. Kockelman. 2014. Estimating bicycling and walking for planning and project development. Number 770 in Nchrp national cooperative highway research pro- 
gram report. Washington, DC: Transportation Research Board of the National Academies. ISBN 978-0-309-28403-5.

Larsen, J., Z. Patterson, and A. El-Geneidy. 2013. Build it. But where? The use of geographic information systems in identifying locations for new cycling infrastructure. International Journal of Sustainable Transportation, 7(4):299-317. Bibtex: larsen_build_2013, URL http://www.tandfonline. com/doi/abs/10.1080/15568318.2011.631098.

Lima, A., L. Rossi, and M. Musolesi. 2014. Coding Together at Scale: GitHub as a Collaborative Social Network. arXiv preprint arXiv:1407.2535.

Lovelace, R., D. Ballas, and M. Watson. 2014. A spatial microsimulation approach for the analysis of commuter patterns: from individual to regional levels. Journal of Transport Geography, 34(0):282296. ISSN 0966-6923. doi: http://dx.doi.org/10.1016/j.jtrangeo.2013.07.008. URL http://www. sciencedirect.com/science/article/pii/S0966692313001361.

Lovelace, R., S. Beck, M. Watson, and A. Wild. 2011. Assessing the energy implications of replacing car trips with bicycle trips in Sheffield, UK. Energy Policy, 39(4):2075-2087. ISSN 03014215. doi: 10.1016/j.enpol.2011.01.051. URL http://linkinghub.elsevier.com/retrieve/pii/ S0301421511000620.

McCollum, D. and C. Yang. 2009. Achieving deep reductions in US transport greenhouse gas emissions: Scenario analysis and policy implications. Energy Policy, 37(12):5580-5596. ISSN 03014215. doi: 10.1016/j.enpol.2009.08.038. URL http://dx.doi.org/10.1016/j.enpol.2009.08. 038.

Melia, S. 2015. Urban Transport Without the Hot Air, Volume 1: Sustainable Solutions for UK cities. ISSN 1906860270.

Minikel, E. 2012. Cyclist safety on bicycle boulevards and parallel arterial routes in Berkeley, California. Accident Analysis \& Prevention, 45:241-247. ISSN 0001-4575.

Novosel, T., L. Perković, M. Ban, H. Keko, T. Pukšec, G. Krajačić, and N. Duić. 2015. Agent based modelling and energy planning-Utilization of MATSim for transport energy demand modelling. Energy. ISSN 0360-5442.

Oja, P., S. Titze, A. Bauman, B. DeGeus, P. Krenn, B. Reger-Nash, and T. Kohlberger. 2011. Health benefits of cycling: a systematic review. Scandinavian journal of medicine \& science in sports, 21(4):496-509. ISSN 1600-0838. doi: 10.1111/j.1600-0838.2011.01299.x. URL http://www. ncbi.nlm.nih.gov/pubmed/21496106.

Parkin, J., ed. 2012. Cycling and sustainability. Number 1 in Transport and sustainability. Bingley: Emerald, 1. ed edition. ISBN 978-1-78052-298-2.

Parkin, J. 2015. Planning and design approaches for cycling infrastructure. Bibtex: parkin2015planning.

Parkin, J., M. Wardman, and M. Page. 2008. Estimation of the determinants of bicycle mode share for the journey to work using census data. Transportation, 35(1):93-109. ISSN 00494488. doi: 10.1007/s11116-007-9137-5. URL http://www.springerlink.com/index/10.1007/ s11116-007-9137-5.

Payne, S. 2014. Removing barriers to direct access. Get Britain Cycling, 4(1):6-8. URL http://www. getbritaincycling.net/wp-content/uploads/2014/04/gbc2015.pdf.

Pettit, C. J., R. E. Klosterman, M. Nino-Ruiz, I. Widjaja, P. Russo, M. Tomko, R. Sinnott, and R. Stimson. 2013. The online what if? Planning support system. In Planning support systems for sustainable urban development, pp. 349-362. Springer. ISBN 3-642-37532-4.

Pikora, T. J., F. C. L. Bull, K. Jamrozik, M. Knuiman, B. Giles-Corti, and R. J. Donovan. 2002. Developing a reliable audit instrument to measure the physical environment for physical activity. American Journal of Preventive Medicine, 23(3):187-194. ISSN 0749-3797, 18732607. doi: 10.1016/S0749-3797(02)00498-1. URL http://www.ajpmonline.org/article/ S0749379702004981/abstract. 
Pucher, J., J. Dill, and S. Handy. 2010. Infrastructure, programs, and policies to increase bicycling: An international review. Preventive Medicine, 50(Supplement 1):S106 - S125. ISSN 0091-7435. doi: DOI:10.1016/j.ypmed.2009.07.028. URL http://www.sciencedirect.com/science/article/ B6WPG-4X7R7X3-3/2/b7dfffcac1645c2943fe03c0a11d5865.

Rae, A. 2009. From spatial interaction data to spatial interaction information? Geovisualisation and spatial structures of migration from the 2001 UK census. Computers, Environment and Urban Systems, 33(3):161-178. ISSN 01989715. doi: 10.1016/j.compenvurbsys.2009.01.007. URL http://linkinghub.elsevier.com/retrieve/pii/S019897150900009X.

Saujot, M., M. de Lapparent, E. Arnaud, and E. Prados. 2016. Making land use - Transport models operational tools for planning: From a top-down to an end-user approach. Transport Policy, 49:2029. ISSN 0967-070X. doi: 10.1016/j.tranpol.2016.03.005. URL http://www.sciencedirect.com/ science/article/pii/S0967070X16300993.

Shergold, I., G. Parkhurst, and C. Musselwhite. 2012. Rural car dependence: an emerging barrier to community activity for older people. Transportation Planning and Technology, 35(1):69-85. ISSN 0308-1060.

Singleton, A. 2014. A GIS approach to modelling CO2 emissions associated with the pupil-school commute. International Journal of Geographical Information Science, 28(2):256-273. ISSN 1365-8816. doi: 10.1080/13658816.2013.832765. URL http: //www.tandfonline.com/doi/abs/10.1080/13658816.2013.832765\$/delimiter"026E30F\$nhttp: //www.tandfonline.com/doi/pdf/10.1080/13658816.2013.832765http://www.tandfonline. com/doi/abs/10.1080/13658816.2013.832765.

Tainio, M., A. J. de Nazelle, T. Götschi, S. Kahlmeier, D. Rojas-Rueda, M. J. Nieuwenhuijsen, T. H. de Sá, P. Kelly, and J. Woodcock. 2016. Can air pollution negate the health benefits of cycling and walking? Preventive Medicine. ISSN 00917435. doi: 10.1016/j.ypmed.2016.02.002. URL http://linkinghub.elsevier.com/retrieve/pii/S0091743516000402.

Tamminga, G., M. Miska, E. Santos, H. van Lint, A. Nakasone, H. Prendinger, and S. Hoogendoorn. 2012. Design of Open Source Framework for Traffic and Travel Simulation. Transportation Research Record: Journal of the Transportation Research Board, 2291(-1):44-52. ISSN 0361-1981. doi: 10.3141/2291-06. URL http://trb.metapress.com/openurl.asp?genre=article\&id=doi:10.3141/ 2291-06.

te Brömmelstroet, M. and L. Bertolini. 2008. Developing land use and transport PSS: Meaningful information through a dialogue between modelers and planners. Transport Policy, 15(4):251259. ISSN 0967070X. doi: 10.1016/j.tranpol.2008.06.001. URL http://linkinghub.elsevier.com/ retrieve/pii/S0967070X08000334.

Tobler, W. R. 1987. Experiments in migration mapping by computer. The American Cartographer, 14(2):155-163. ISSN 0094-1689.

Transport for London. 2010. Analysis of Cycling Potential. Technical report, Transport for London. URL http://www.tfl.gov.uk/cdn/static/cms/documents/analysis-of-cycling-potential.pdf.

Transport for London. 2015. London Cycling Design Standards (LCDS). Technical report. URL https://www.tfl.gov.uk/corporate/publications-and-reports/streets-toolkit.

Wegman, F. C. M. 1979. Urban planning, traffic planning and traffic safety of pedestrians and cyclists. In Contribution to the OECD-symposium in Safety of Pedestrians and Cyclists, Paris. URL http: //www.swov.nl/rapport/R-79-07.pdf.

Welsh Government. 2014. Guidance Active Travel (Wales) Act. Technical report, Welsh Government, Cardiff. URL Guidance.

Wood, J., J. Dykes, and A. Slingsby. 2010. Visualisation of origins, destinations and flows with OD maps. The Cartographic Journal, 47(2):117-129.

Woodcock, J., R. Aldred, A. Goodman, R. Lovelace, A. Ullrich, A. Abbas, and N. Berkoff. 2016. National Propensity to Cycle Tool Project: Summary Report. Technical report, Department for Transport. URL https://www.gov.uk/government/publications/ 
national-propensity-to-cycle-first-phase-development-study.

Woodcock, J., P. Edwards, C. Tonne, B. G. Armstrong, O. Ashiru, D. Banister, S. Beevers, Z. Chalabi, Z. Chowdhury, A. Cohen, O. H. Franco, A. Haines, R. Hickman, G. Lindsay, I. Mittal, D. Mohan, G. Tiwari, A. Woodward, and I. Roberts. 2009. Public health benefits of strategies to reduce greenhouse-gas emissions: urban land transport. The Lancet, 374(9705):1930-1943. ISSN 01406736. doi: 10.1016/S0140-6736(09)617141. URL http://dx.doi.org/10.1016/S0140-6736(09)61714-1http://www.ncbi.nlm.nih.gov/ pubmed/19942277http://linkinghub.elsevier.com/retrieve/pii/S0140673609617141.

Zhang, D., D. J. A. V. Magalhaes, and X. C. Wang. 2014. Prioritizing bicycle paths in Belo Horizonte City, Brazil: Analysis based on user preferences and willingness considering individual heterogeneity. Transportation Research Part A: Policy and Practice, 67:268-278. ISSN 09658564. doi: 10.1016/j.tra.2014.07.010. URL http://linkinghub.elsevier.com/retrieve/pii/ S096585641400175X. 